\title{
Does Gender Matter? Student Mobility in Georgia. A Case Study
}

\section{Ekaterine Beniashvili*}

Jan Böhm**

\begin{abstract}
While integration into the European Union is one of the priorities of Georgia, internationalization of higher educational institutions and international student mobility is of a particular importance. The present paper serves exactly this purpose and outlines the preliminary assumption that gender stereotypes, cultural aspects and family traditions have a negative impact on students' equal access to student exchange programs in Georgia. Although female students are more involved into international student exchange programs, they are at the same time facing bigger obstacles to do so. The mentioned problem refers mainly to females who cannot decide the issue of their participation in exchange programs alone, without their family's involvement. The study revealed that the participation of female students in exchange programs especially increases year by year, while only a slight increase of the number of male students is demonstrated. The mentioned finding is in absolute coincidence with the events in Europe, where female participation has exceeded male participation long ago. In the light of the fact that this issue has never been studied before, the present paper may somewhat complement the gap in literature or build a foundation for the research in this field, as it discusses the individual factors of refusal to participate in exchange programs by female students, as well as interruptive and hindering circumstances, which in most cases come from family.
\end{abstract}

Keywords: student mobility, higher education, gender, Georgia

\section{Introduction}

Since 2005, when Georgia joined the Bologna Process, there has been an increase in the number of programs that give students at Georgian HEls the opportunity to obtain funding for higher education abroad. Consequently, the number of students interested in these opportunities or involved in the mobility process has also increased. However, students face a number of disruptive and hindering circumstances. One of them is gender inequality.

The goal of the present study is to discuss and identify gender issues related to participation in exchange programs abroad. In the light of the fact that this issue has never been studied before, the present paper may somewhat complement the gap in literature or build a foundation for research in this field.

The preliminary assumption of the study is that gender stereotypes, cultural aspects and family traditions have a negative impact on students' equal access to student exchange programs in Georgia (the mentioned problem refers mainly to female students in Georgia who cannot decide the issue of their participation in exchange programs alone and without their family's involvement).

\footnotetext{
* Researcher, East European University, Tbilisi, Georgia

**Prof. Dr. University of Education Upper Austria, Linz, Austria
} 
The target group of the study is female and male undergraduate and graduate students at the HEls of East Georgia. In order to ensure the validity of the study, it was important that the participants should be from different cities of East Georgia. The participants were selected from Tbilisi, Gori and Telavi universities. It was not necessary for the research participants to be part of the exchange program, thus making this important factor an independent variable.

\section{Mobility as an opportunity to internationalize individual students as well as universities}

As stated in the 2012 study Higher Education in Georgia (European Commission, 2012), the vast majority of Georgian studentsinvolved in mobility study in the USA, Germany and the UK, followed by some other EU countries. The same study shows that programs supporting mobility of Georgian students are mainly financed by international donors (Erasmus Mundus, German Academic Exchange Service - DAAD, British Council, International Research and Exchanges Board - IREB, International Research \& Exchanges Board - IREX, Open Society Georgia Foundation - OSGF, United States Agency for International Development USAID).

The EU grant program Erasmus+ differs from other programs run in Georgia in terms of scale and easy accessibility. Its official website (http://erasmusplus.org.ge/ge/for-students) says that in 2014-2020, projects have been implemented in the fields of education, training, youth and sports. The program aims to modernize education, increase the level of knowledge and employment, provide training and work with young people in the country.

In addition, within degree mobility, Erasmus scholarships were awarded to 8 Georgian citizens for joint masters programs in 2015, 15 in 2016 and 21 in 2017. Erasmus, which De Wit calls the "driver" of European internationalization (De Wit, 2013. p. 19), aims to become a bridge between education and the labor market.

In 2009, the Ministerial Conference of EHEA member states (Eurostudent, 2016) endorsed a policy goal, according to which $20 \%$ of graduates from higher education should have experience of studying or training abroad. The mentioned goal is still upheld today (EHEA Mobility Strategy, 2012). Some educational institutions (e.g. Goucher College and St. Mary's College in Maryland, USA) provide international education which also includes international research, a compulsory part of the education and a necessary condition for obtaining a degree (Strout, 2010).

As defined by Orr (2013), a mobile student is a person who has crossed a border and has been enrolled in a foreign university or college for at least 12 months, and the mentioned process is beneficial not only to the mobile student, but also to the recipient institution, as it ensures the internationalization of the university.

This assumption gives us reason to think that if universities in Georgia improve their ability to create standards-based programs for mobile students delivered in foreign languages, Georgian students will be more likely able to develop skills that are characteristic of a multicultural society, to increase their tolerance and, most importantly, to increase their motivation to participate in exchange programs.

\section{Participation in exchange programs, according to gender}

Obstacles to access to higher education for women begin with the process of choosing their profession. The UNDP 2013 report on gender equality in politics and business research includes family barriers to academic education, where priority can be given to the education of the son in the family if it is a matter of choice. Other factors, such as early marriage, should also be considered: $17 \%$ of Georgian women marry before they turn 18 years old (National Review of the Implementation of the Beijing Declaration and Platform for Action, 2014, p. 19), pregnancy and in general the role of women in the country, which mainly focuses on family care (ibid, p. 16). 
There is less public expectation of career growth for women, which greatly impacts gender segregation trends in Georgia. Here, taking care of the family takes the top spot among the duties of a woman (Gorgadze, 2016). According to the UNDF (2013) survey, $74 \%$ of the population consider that the woman's main value should be her family.

As in higher education, equality between men and women in exchange programs has long been on the agenda in various countries. Historically, countries have fought to increase women's participation before reaching the point at which female participation exceeds that of men in most European countries. Research shows that women in Germany are slightly more likely to engage in higher education abroad than men, which means that it is necessary to encourage men as well gender equality has to be achieved (Wächter, Lam, \& Ferencz, 2012).

A study with participation of Erasmus program participants in 2011-2012 also outlines gender imbalances in favor of women and the need to empower men in this regard (Böttcher et al., 2016). The European Commission website says that, in 2012-2013 (EC 2014), 60.6\% of Erasmus participants were women and, in 2013-2014, 61\% (http://ec.europa.eu/education/resources/statistics_en), just as in 2015-2016.

A 2014 research on student mobility in the European higher education area by the Vienna Research Institute (Grabher, Wejwar, Unger, \& Terzieva, 2014) found that almost in all countries, women's participation in mobility (credit mobility) is higher than that of men. Student flow is unbalanced (degree mobility) in the case of mobility from Eastern European countries, though gender issues are not emphasized there, partly because the same study suggests that access to data collected from Eastern European countries is limited and not qualitative (Grabher et al., 2014).

A 2012 study sponsored by the German Ministry of Education and Research (Netz, Orr, Gwosć, \& Huß, 2012) says that the major obstacles are socio-demographic problems, which include age, gender and education level. The current situation tells us that female students are more likely to engage in study abroad, although the impact of age is felt by young females as their chances of becoming pregnant increase with age. Consequently, their opportunities to study abroad are diminishing and studying abroad is becoming more and more difficult.

In order for women to reconcile their academic career with their family life, they often subordinate their careers to their partner's, which impedes their academic progress (Uhly, Visser, \& Zippel, 2017). Several studies show that in addition to marital status and partner's job, parental or guardian's involvement may have an effect on the international academic mobility and cooperation of men and women (Ackers, 2008).

The Erasmus Student Network's (2015) regions surveys state that one of the major impediments is family resistance, and this is related to the age of students. However, it is necessary to find out whether this problem has any connection with gender issues, as various studies (e.g. Gorgadze, 2016) show unjust attitudes towards women in Georgia in general as well as in the field of education. Family as a factor impeding education abroad is particularly common in some regions (Gori: 75\%; Zugdidi: 67\%) according to the above-mentioned research. This confirms the need to investigate this field and take effective steps to remedy the situation.

\section{Research methodology}

This study was undertaken using a mixed methods approach (see Creswell, 2012), using qualitative as well as quantitative methods. In addition, we evaluated numerous documents and statistics. 
In the course of the study, three focus group interviews were held with groups of between 6 and 10 students (male and female), respectively (Gori Teaching University, lakob Gogebashvili Telavi State University and East European University Tbilisi). Further questionnaires were sent out to the Georgian Technical University, Ivane Javakhishvili Tbilisi State University as well as lakob Gogebashvili Telavi State University. Aside from this, expert interviews were held with staff (all female) of the Erasmus or international offices of all involved universities. In-depth interviews and focus groups were used, and content analysis (statistical data obtained from the National Statistics Office of Georgia and the HEls participating in the study) became a source to uncover additional issues.

The study involved male and female participants, graduate and postgraduate students and administration officials from Tbilisi Ivane Javakhishvili State University, Ilia State University, Georgian Technical University, Gori Teaching University, Telavi lakob Gogebashvili State University and two private HEls in Tbilisi: East European University and University of Georgia. Erasmus+ program selection criteria were used as criteria for participation in the study, i.e. English language skills better than average and high GPA. In addition, research participants had to be students of programs for which the university has announced exchange programs. One of the important factors considered when selecting the participants was their willingness and interest.

The results of the study were analyzed by coding methods. The coding of the obtained data was carried out to account for three issues: exchange programs and gender balance; personal factors for refusal to participate; obstructing external factors.

\section{Research Results}

In order to further deepen the understanding of gender issues encountered in Georgia in relation to exchange programs, we sought to find out how well the gender balance between the participants in these programs is maintained and what the stakeholders themselves think about it.

According to Geostat (2020), in 2017-2018 academic year there were 583 Georgian students studying abroad (394 of them female students), in 2018-2019 academic year there were 673 students (418 of them female students), and in $2019-2020$ academic year the number of Georgian students studying abroad was 656 (446 of them were female students). All three years the number of female students significantly exceeds the number of male students.

The increase in student participation in exchange programs is caused by the increase in the number of exchange programs, improved funding and information dissemination. This is confirmed by interviews with university officials and the Erasmus office. However, we cannot expressly exclude the growing interest of female students, as well as their empowerment and support from parents and the community, as evidenced by talking with the students. Considering the number of male and female students by university, based on the public information provided by them, circumstances do not change radically at this stage if we compare it with the current situation. Three sides, university officials, the Erasmus office and students agree on one issue: that gender balance among exchange program participants in Georgia is in favor of female students. This means that every year more female than male students participate in exchange programs. Only one HEl diverged in this regard, where we were told that gender balance was maintained.

For example, according to the information received from Ivane Javakhishvili State University, since 2015, they have sent 617 students abroad, 454 female and 163 male students. This means that $73 \%$ of exchange program participants are female students. The number of outgoing students has increased compared to 2015-2016, although participation of male students has 
not changed. As for 2017-2018, the number is almost identical to the number of the previous year (the number of female students increased by one person and the number of male students decreased by two).

Full information on only two academic years has been received from Ilia State University. This also shows the increasing tendency of female students (exceeding the number of male students by 50 participants in 2016-2017 and by 63 in 2017-2018) to participate in exchange programs. That means that in both years, 103 out of 233 participants, i.e. $74 \%$, were women. Gori Teaching University, like other universities mentioned above, is reporting more involvement by female students. The exchange programs have been attended by 35 students since 2015 and the majority of the participants have been female. Only 6 out of 35 students have been male, which means that about $85 \%$ of the participants have been women.

An interesting case to consider is that of the Georgian Technical University, where, due to the specifics of the faculties and the traditional concept of the so-called 'female and male professions', the majority of students are male. Notwithstanding the above, the number of female students participating in the exchange program ( 34 female students in total) is only slightly lower than the number of male students. In total, of 78 outgoing students from the Georgian Technical University since 2015, 44, i.e. $56 \%$, were men.

Overall, women are overrepresented in higher education mobility, although this is somewhat mitigated by a view of the general gender balance of students: except at the Georgian Technical University, the gender ratio of all students is approximately 65/35; this means that women are strongly overrepresented at HEls, even though there are considerable variations between individual programs.

\section{Exchange programs and gender balance}

The number of exchange program participants in Georgia is increasing. This is due to the increase in exchange programs and funding, although it should be emphasized that the participation among female students is particularly high, while the number of male students is only slightly increasing. This is in complete synchrony with developments in the EU, where female participation has long exceeded male participation in many countries. Separate research is needed on why male interest is lacking and what is needed to activate and engage them in different activities. Many HEls do not keep statistics by gender of applicants, which hindered our investigation to determine whether the low participation of men is due to their low interest or their academic performance; the latter opinion was voiced by an administrator at one of the HEls.

\section{Personal factors for refusal to participate}

During the course of the study, the problem of self-esteem among female participants was clearly identified. They are not sure how they can handle living in a foreign country. Foreign countries are associated with threat and do not represent a challenge that they would wish to overcome. This can be related to the family tradition of raising girls. Gaps in school textbooks on gender roles and low gender sensitivity among school teachers should also be noted. All these factors can affect a girl who, from a young age, is determined by what is 'appropriate', how she should behave, what role she plays, and what her family and relatives expect from her.

The research design did not initially identify personal factors that prevent students from participating in exchange programs. However, during the focus group process, some important issues were identified which are worth mentioning.

In the case of male students, this is willingness. As the focus groups have shown, they think that "if they wish, they can do everything" - but "perhaps this is not the right time for them". It seems that parental opposition should not be a problem for 
them when making any decisions. They seem to be more dependent on themselves than on family, parents, etc. However, as we were told in Erasmus + office, the number of male students who approach the issue "keenly" and with full responsibility is smaller.

We have to confront the situation of females' self-esteem, which has to do with the family tradition of raising girls and other factors. In Georgian historical sources, we find that Georgian women have been made responsible for the moral purity of the Georgian people for a long time. They were seen as devoted to their families' mothers. "Their (Georgian women's) motherhood, dedication to the motherland, honesty combined with physical beauty, high morale was a symbol of the conscience of their homeland" (Kiknadze \& Donadze, 2006, p. 82). "In almost every field of activity, women were left out of decision-making" (ibid, p. 85).

The shortcomings in school textbooks may appear exactly in this form, as an analysis of elementary school textbooks from a gender perspective shows (Tabatadze \& Gorgadze, 2013). Textbook illustrations and texts were studied according to different criteria, including the content of gender stereotypes in portraying male and female natures, activities and roles such as marital status or professional activity (p. 46). The study says that school textbooks are generally characterized by unequal gender representation and reinforce stereotypes in society about the role of men and women in the family (p. 72). To this we must add the extremely low gender sensitivity of teachers, which is a problem in Georgia. The study of teachers' knowledge and attitudes towards gender (Isakadze \& Gvianishvili, 2014, p. 11) shows that the majority of the respondents favor traditional distribution of male and female roles. Teachers themselves use stereotypes when analyzing the distribution of gender roles, for example, they think that family and motherhood, rather than professional advancement, is important for a woman, and they believe that the man first of all should provide the family financially.

During the focus groups interview, one could often hear the phrases from women: "will I be able to?", "I am afraid that I will be alone", or "I don't want to be far from my homeland". The hindering factors for exchange program participation for them are 'a life far from familiar people', 'a completely self-reliant life', a 'fear of insecurity', and 'foreignness itself'. These comments clearly show that, for women, leaving the country is sometimes an insurmountable problem. A foreign country is associated with threats, not an opportunity to know the world.

In some cases, the students themselves give up the very thought of going abroad. This would be the reason why university officials may not be aware that their students have any problems with their families in cases where there is no evidence of familial opposition against the girl going to study abroad.

\section{Obstructing external factors}

According to the study, male students are less likely to be restricted by their families when they decide to continue their studies abroad. However, more female students experience a limitation than male students and this limitation can take one of three forms:

- they already know from past experiences what to expect from their family members and therefore do not express their desire or try their luck;

- they speak out, although they experience a sharp reaction from family members, but eventually do not or cannot go against their will;

- they speak out and despite reactions do not give up.

When it comes to restrictions, it should be noted that there are instances in which the problem concerns a female student in the family, while a male student living in the same family enjoys more freedom. 
We were interested in the reasons parents give for creating obstacles, and among these reasons are:

- $\quad$ security and terrorism;

- lack of skills needed for their daughter to immerse herself in a foreign environment;

- fear that a European experience may have a negative effect on their daughter.

"My father thinks it is possible to get enough knowledge in one's home country, in this case in Georgia, and he is against continuing studies abroad."

As stated by the Erasmus office, the mentioned issues are rarely found in East Georgia, though such cases are quite common in West Georgia and in regions populated by ethnic minorities.

"We had such cases in Kutaisi, Batumi and Zugdidi... The reason for not being permitted to go by the family may, on the one hand, be concerns about how secure their virginity will be; this was said in West Georgia and we have heard about such cases, but we have not done any research on this. They don't even submit an application because they know the parents won't let them go. This topic has not been raised in East Georgia. To be more precise, such information has not reached us."

Ethnic minorities are particularly open about their daughters' so-called "virginity status", while in Eastern Georgia they do not speak about it so openly and are limited in their means of resistance. As a rule, parents and especially fathers who prevent their daughters from participating in exchange programs also oppose working, leaving home in the evening, etc. "My father won't let me go to work in my city and you think he will send me to another country?"

In conclusion, it should be noted once again that the existence of obstacles for female students in today's Georgia is still a reality. However, universities are often unaware that there are problems in their families, such as family breakdown and parental resistance.

And finally, as the study covered only Eastern Georgia, these problems have only been identified in Eastern Georgia. However, specialists in the field say the issue is particularly acute in Western Georgia and regions populated by ethnic minorities. This requires additional research and a response from both education policy makers and HEls.

\section{Conclusion and Recommendations}

At first glance, the study shows a contradictory result: on the one hand, females are in the majority among the exchange students both absolutely and relatively at all investigated institutions. On the other hand, as the findings of this study show, it is primarily female students who face structural disadvantages in opting to study abroad. In particular, stereotyped views of the female gender, which are still being propagated in schools, obstruct the mobility of female students. It must be noted that both genders face certain socioeconomic barriers, but these can relatively easily be mitigated through specific support measures (bursaries, etc.). The described conservative views on gender in many families, however, are much more powerful and ultimately liable to cement gender imbalance.

Even though the study does not claim to be representative, it is possible to formulate a few justified statements:

- At all investigated institutions, female students participate in higher education mobility in greater numbers, both absolutely and relatively, than male students.

- As soon as the financial burden of mobility is counteracted through structural support, mobility numbers increase 
- Doubts about studying abroad are, for female students, the result of various fears regarding the factors of social isolation, self-sufficiency, homesickness and security. A possible explanation can be found in the very strong sense of family unity in Georgian society. Individual lifestyles, as they can be found in developed Western countries, exist only as a marginal phenomenon in Georgia and do not in any way reflect the majority of the population.

- The above-average rate of participation of female students conceals (family-related) structural disadvantages for women concerning higher education exchanges. In some cases, female autonomy is overruled by traditional conceptions of femininity in the family, and this can in some cirumstances lead to the suppression of the wish to study abroad.

- These traditional (patriarchal) conceptions of femininity are passed on, built up and reinforced not only within nuclear families, but also in school, for instance, by using textbooks promoting traditional gender roles. And this occurs irrespective the fact that the great majority of all teachers across all school types are women.

These findings cannot claim to be representative. They do, however, confirm the findings of the existing previous studies (of which only a few were held in Georgia). This topic has not been dealt with sufficiently in scientific research. Many of the subjects broached require more in-depth research. The very quantitative success of female students in higher education mobility can obscure the structural disadvantages of women and thus impede educational opportunities for women.

The following recommendations can be made on the basis of this study:

Conducting, disseminating and promoting research: for the purposes of field development and deeper and more systematic research in this field. It is important that education administrators become more involved in research and support the work of other researchers. The fact that the demand for exchange programs at all HEls is so high that the participation of female students exceeds the participation of male students by a very large margin does not mean that the problem can be neglected. If HEls become more interested in research and subsequently become more aware of research results, they will be able to respond appropriately, plan activities and actively engage students and staff.

Information campaigns and raising awareness: although education administrators are less aware of the problems of female participation, they can be given a common recommendation: planning information campaigns and raising parental awareness that the problem of female participation actually exists. In addition to giving parents full information about exchange programs and their benefits, it is even more important to convince them to start empowering their daughters and starting to develop the skills they need at an early age.

Development of educational programs, internationalization: this recommendation applies not only to higher education institutions but also to those interested in education policy makers in the country. As we have already discussed, not only exchange students benefit from student mobility, but it also contributes to the internationalization of local community, implying changes in the attitudes of the locals. 


\section{References}

Ackers, L. (2008). Internationalisation, mobility and metrics: A new form of indirect discrimination? Minerva, 46 (4), 411-435. https://doi.org/10.1007/s11024-008-9110-2

Böttcher, L., Araulo, N.A.M., Nagler, J., Mendes, J.F.F., Helbing, D., Herrmann, H.J. (2016). Gender Gap in the ERASMUS Mobility Program. PLoS ONE 11(2): e0149514. https://doi.org/10.1371/journal.pone.0149514

Creswell, J.W. (2012). Educational Research. Planning, Conducting, and Evaluating Quantitative and Qualitative Research. 4th ed. Boston, M.A: Pearson.

De Wit, H. (2013). An Introduction to Higher Education. Milan: Universitã Cattolica del Sacro Cuore. Center for Higher Education Internationalisation.

Eurostudent. (2016): Intelligence Brief No. 2. What are the Obstacles to Students Mobility During the Decision and Planning Phase? Retrieved June 20, 2020 from https://www.eurostudent.eu/download_files/documents/EV_IB_mobility_obstacles.pdf

European Commission. (2012): Higher Education in Georgia. 2012. Tempus. Retrieved January 20, 2019 from http://erasmusplus.org.ge/files/publications/Georgia\%20Country\%20Fiche\%202012\%20-\%20en.pdf

European Commission (n.d.). What is Erazmus+? Retreived July 1, 2020 from https://ec.europa.eu/programmes/erasmusplus/about_en\#tab-1-5

Erasmus Students' Network. (2015). Erasmus Survey of Regions for 2014-2015. Tbilisi: Erasmus+ National Office.

Gorgadze, N. (2016). Sqesobrivi tanasworoba saqartveloshi: zogadi konteqsti da statistika [in Georgian: Gender Equality of Georgia: General Context and Statistics]. Tbilisi. Retreived July 1, 2020 from https://www.academia.edu/26732173/\%E1\%83\%92\%E1\%83\%94\%E1\%83\%9C\%E1\%83\%93\%E1\%83\%94\%E1\%83\%A0\%E1 \%83\%A3\%E1\%83\%9A\%E1\%83\%98_\%E1\%83\%97\%E1\%83\%90\%E1\%83\%9C\%E1\%83\%90\%E1\%83\%A1\%E1\%83\%AC\%E1\% 83\%9D\%E1\%83\%A0\%E1\%83\%9D\%E1\%83\%91\%E1\%83\%90_\%E1\%83\%96\%E1\%83\%9D\%E1\%83\%92\%E1\%83\%90\%E1\%8 3\%93\%E1\%83\%98_\%E1\%83\%99\%E1\%83\%9D\%E1\%83\%9C\%E1\%83\%A2\%E1\%83\%94\%E1\%83\%A5\%E1\%83\%A1\%E1\%83 \%A2\%E1\%83\%98_\%E1\%83\%93\%E1\%83\%90_\%E1\%83\%A1\%E1\%83\%A2\%E1\%83\%90\%E1\%83\%A2\%E1\%83\%98\%E1\%83 \%A1\%E1\%83\%A2\%E1\%83\%98\%E1\%83\%99\%E1\%83\%90

Grabher, A., Wejwar, P., Unger, M., \& Terzieva, B. (2014). Student Mobility in the EHEA. Underrepresentation in Student Credit Mobility and imbalances in degree mobility. Institute for Advanced Studies, Vienna.

Isakadze, T. \& Gvianishvili, N. (2014). Study of Teachers' Knowledge and Attitudes towards Gender Equality. Tbilisi:Training and Research Group Project "Implementing Gender Equality in Schools".

Kiknadze, T. \& Donadze, N. (2006). Gender - Social and Political Studies, Tbilisi: Center for Social Sciences.

National Review of the Implementation of the Beijing Declaration and Platform for Action (2014). Georgia - Beijing +20 . Retrieved $\begin{array}{lllll}\text { June } & 25, & 2020 & \text { from }\end{array}$ http://www.unece.org/fileadmin/DAM/Gender/publications_and_papers/Georgia_Beijing_20_National_Review_Final_M ay_5_1_F.pdf.pdf

Netz, N., Orr, D., Gwosć, C., Huß, B. (2012). What deters students from studying abroad? Evidence from Austria, Switzerland, Germany, the Netherlands and Poland. Bonn: Institute of Higher Education, Federal Ministry of Education and Research of Germany. 
Orr, D. (2013). Where do internationally mobile students come from and where do they go? An overview of the flows of internationally mobile students. In: EAIE-Handbook - Internationalisation of European Higher Education. Retrieved June 25, 2020 from https://www.handbookinternationalisation.com/de/handbuch/gliederung/?articleID=353\#/Beitragsdetailansicht/190/353/Where-dointernationally-mobile-students-come-from-and-where-do-they-go\%253F---An-overview-of-the-flows-ofinternationally-mobile-students

Strout, A.H. (2010). Who Plans (Not) to Study Abroad? An Examination of U.S. Student Intent. Amherst, MA: University of Massachusetts.

Tabatadze, S. \& Gorgadze, N. (2013). Research of Intercultural Education Aspects of Elementary Schools in Georgia. Tbilisi: Center for Civil Integration and Inter-Ethnic Relations.

Uhly, K.M., Visser, L.M., \& Zippel, K.S. (2017). Gendered patterns in international research collaborations in academia. Studies in Higher Education, 42 (4), 760-782, DOI: 10.1080/03075079.2015.1072151

UNDF. (2013). The Millennium Development Goals Report. https://www.un.org/millenniumgoals/pdf/report-2013/mdg-report2013-english.pdf

UNDP. (2013). Public Perceptions on Gender Equality in Politics and Business. Tbilisi. Retrieved June 25, 2020 from https://www.ge.undp.org/content/georgia/en/home/library/democratic_governance/public-perceptions-on-genderequality-in-politics-and-business.html

Wächter, B., Lam., Q.K.H., \& Ferenczi, I. (Eds.). (2012). Tying It All Together. Excellence, Mobility, Funding and the Social Dimension in Higher Education. ACA Papers on International Cooperation in Education. Bonn: Lemmens. 